\title{
Expression of the common acute lymphoblastic leukaemia antigen (CALLA gp100) in the brush border of normal jejunum and jejunum of patients with coeliac disease
}

\author{
LK TREJDOSIEWICZ, G MALIZIA, JANE OAKES, MS LOSOWSKY, G JANOSSY* \\ From the Department of Medicine, University of Leeds, St James's Hospital, Leeds and the *Academic \\ Department of Immunology, Royal Free Hospital School of Medicine, London
}

SUMMARY Expression of the gp100 common acute lymphoblastic leukaemia antigen (CALLA) was studied in the mucosa of the gut by means of indirect immunofluorescence on cryostat tissue sections with a panel of eight monoclonal antibodies to common acute lymphoblastic leukaemia antigen (anti-CALLA antibodies) and two antibodies to non-CALLA leukaemic antigens. Expression of CALLA was absent from normal stomach epithelium, adult and fetal colonic epithelium of normal histology, and colonic epithelium from patients with Crohn's disease or ulcerative colitis. By contrast, all eight anti-CALLA antibodies gave a characteristic reaction in normal adult and fetal small bowel mucosa, with specific localisation to the entire brush border of jejunal epithelium. Whereas seven of these antibodies reacted both with normal jejunal epithelium and with the damaged epithelium of patients with coeliac disease, antibody RFAL-2 reacted strongly only with histologically normal small bowel but more weakly in patients with coeliac disease to a degree related to the amount of histological abnormality. Expression of the moeity like CALLA identified with RFAL- 2 was strongest in crypt epithelium and proportionally diminished along the villi according to the amount of histological damage in coeliac disease, being essentially absent in patients with "subtotal villous atrophy."

The 100 kilodalton common acute lymphoblastic leukaemia antigen (CALLA, gp100) was first defined by means of xenoantisera. ${ }^{\prime}$ Regarded as a probable marker for early lymphoid progenitor cells, CALLA was soon detected on a minority population of normal bone marrow precursor cells ${ }^{2}$ which express the phenotype of common acute lymphoblastic leukaemia. ${ }^{3}$ CALLA is therefore now regarded as a transiently expressed stem cell antigen, immortalised on leukaemic cells as part of their expression of a "frozen" neoplastic phenotype..$^{23}$ With the advent of monoclonal anti-CALLA antibodies $^{4-7}$ it became clear that CALLA was not restricted to cells of lymphoid lineage: CALLA has now been shown on polymorphonuclear neutrophils, ${ }^{8}$ granulocytes, ${ }^{9}$ kidney tubular epithelium, glomeruli and breast myoepithelium, ${ }^{10}$ melanoma ${ }^{11}$ glioma cells, ${ }^{12}$ and cultured fibroblasts. ${ }^{9}$

Accepted for publication 16 May 1985
In view of the known characteristic reactivity of anti-CALLA antibodies on the brush border of kidney epithelium ${ }^{10}$ we aimed to investigate the expression of antigens like CALLA by the enterocytes of the small intestine as a correlate of mucosal damage associated with conditions such as coeliac disease. The specialised columnar epithelium cells of the jejunum are characterised by a microvillous brush border on the luminal (apical) surface and play a vital part in the absorption of nutrients, probably through several enzymatic and passive and active transport mechanisms. ${ }^{13}$ In coeliac disease severe malabsorption is accompanied by profound morphological change of the jejunal mucosa: the villi are shorter and broader and may be entirely absent, whereas the epithelial cells become cuboidal rather than columnar and the microvilli are shorter and less regular. ${ }^{14-16}$ Treatment by total avoidance of gluten usually brings about an eventual restoration of normal macroscopic and ultrastructural morpho- 
Reactivity of anti-CALLA monoclonal antibodies in jejunum

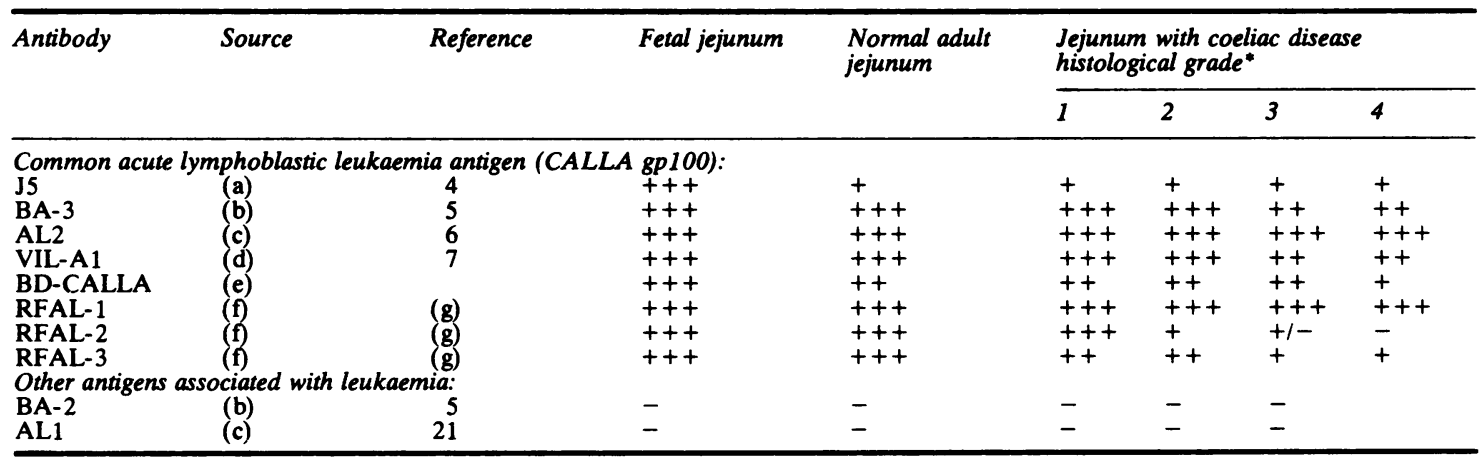

Immunofluorescence reaction was scored subjectively from negative $(-)$ to strong positive $(+++)$.

${ }^{*}$ Histological classification based on that of Scott and Losowsky. ${ }^{18}$

(a) Coulter Clone (Coulter Electronics Ltd, Luton).

(b) Gift of Dr J Kersey, University of Minnesota.

(c) Gift of Dr AM LeBacq-Verheyden, University of Brussels.

(d) Gift of Professor W Knapp, Institute of Immunology, Vienna.

(e) Becton Dickinson (Laboratory Impex Ltd, Twickenham).

(f) RF-series monoclonal antibodies are available directly from Professor G Janossy (Royal Free Hospital, London).

(g) Professor G Janossy et al (in preparation) (Royal Free Hospital, London).

$\operatorname{logy} .^{15-17}$ In this report we show the strong expression of a moeity related to CALLA in the brush border of jejunal enterocytes and show that one anti-CALLA monoclonal antibody, RFAL-2, is a very sensitive marker of damage to small bowel epithelium in coeliac disease.

\section{Material and methods}

\section{PATIENTS AND TISSUE SPECIMENS}

Specimens of tissue from 42 patients were examined. Peroral jejunal biopsies were obtained from 28 patients. Of these, 17 had been diagnosed as having coeliac disease, of whom seven were untreated and had severe (grade 3 ) or subtotal (grade 4) villous atrophy. ${ }^{18}$ All seven were subsequently shown to have a morphological response to a diet free of gluten. The remaining 10 patients, previously diagnosed as suffering from coeliac disease, ranged in morphology from severe villous atrophy (grade 3, three cases) and partial villous atrophy (grade 2, five cases) to essentially normal (grade 1, two cases). Of the remaining 11 patients, three had inflammatory bowel disease (one colitis, two Crohn's ileitis) but normal (grade 1) jejunal mucosa, and eight were regarded as "normal" controls (five irritable bowel syndrome, one fibrosing alveolitis, one iron deficiency anaemia, and one macrocytic anaemia).

Gastric biopsies from the body and antrum were obtained from two patients with normal histology. Colonic biopsies were obtained at colonoscopy from three patients with Crohn's disease and three patients with ulcerative colitis. Samples of normal colonic mucosa were obtained at resection from four patients with diverticular disease and two patients with colorectal carcinoma. Finally, tissue from the large and small intestine of fetus of 16 weeks' gestation was also studied.

Resection samples were dissected free of the muscularis propria; all samples of tissue were orientated, coated in ornithine carbamoyltransferase compound, snap frozen in thawing isopentane, cut into sections of $5 \mu \mathrm{m}$ by cryostat. Sections were thoroughly dried in air and stored dessicated at $-70^{\circ} \mathrm{C}$. Some sections were fixed in chloroform: acetone (1:1) mixture before drying and storage.

\section{IMMUNOFLUORESCENCE}

The 10 monoclonal antibodies to antigens associated with leukaemia used in this study are listed in the Table. Eight of these antibodies were specific to the 100 kilodalton (gp100) CALLA antigen. The three RFAL anti-CALLA antibodies were obtained after fusion, induced by polyethylene glycol, ${ }^{19}$ of splenocytes from mice immunised with the NALM-6 common acute lymphoblastic leukaemia cell line ${ }^{20}$ with NS0/1 plasmacytoma cells. ${ }^{19}$ Hybrid clones were initially screened by immunofluorescence on sections of tissue and subsequently characterised by flow cytofluorimetry. Two non-CALLA antibodies raised to leukaemic cells were also included for control purposes-namely, antibodies BA- $2^{5}$ and $A L 1,{ }^{21}$ which react with antigens associated with leukaemia of 24 and 120 kilodaltons, respectively. 


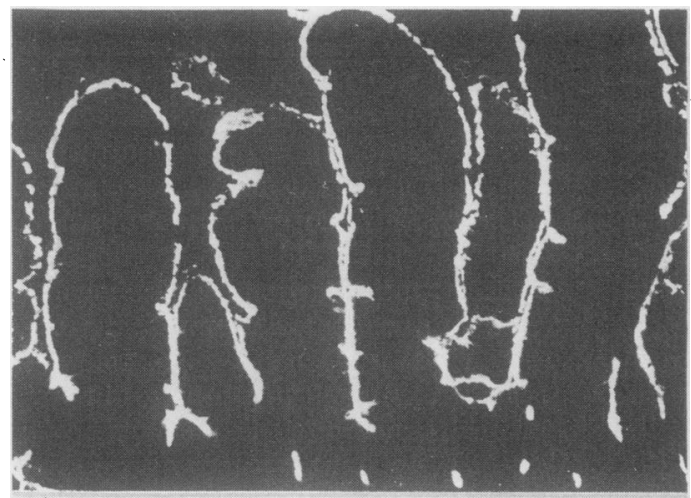

Fig 1

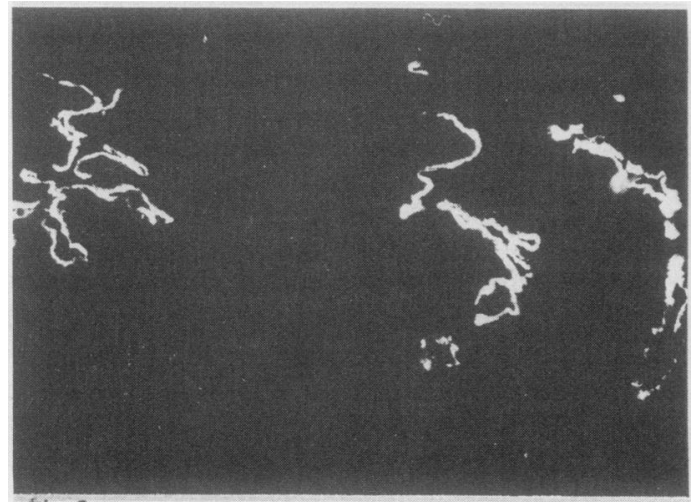

Fig 3

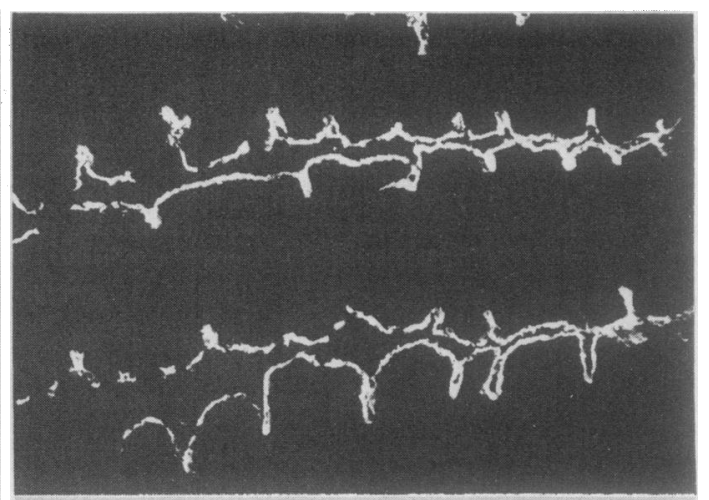

Fig 2

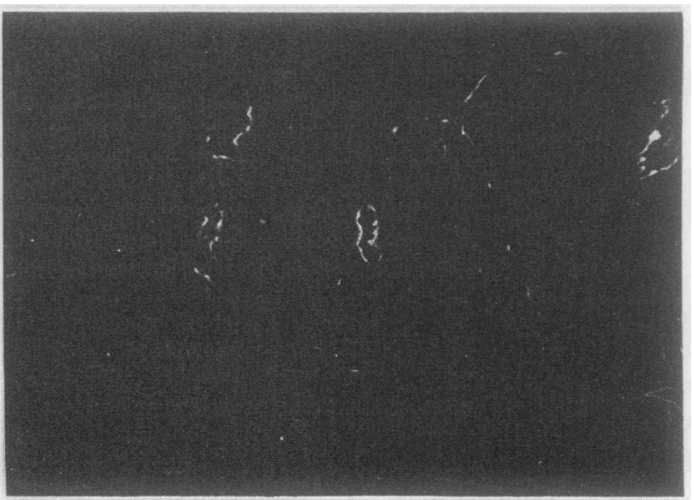

Fig 4

Fig. 1-4 Immunofuorescence of adult jejunum with anti-CALLA antibody RFAL-2. Micrographs were taken on Ilford HP5 emulsion with $\times 16$ or $\times 25$ Plan-Neofuar immersion lens, Zeiss standard 18 microscope.

Fig. 1 Normal jejunum (grade 1 histology) from patient with irritable bowel syndrome. Antibody reaction is strong and confined to brush border of crypt and luminal epithelium.

Fig. 2 Jejunum from patient taking gluten free diet that is virtually normal (grade 1 histology). Immunolocalisation pattern is almost identical to that of normal jejunum, although tips of villi labelled slightly less strongly.

Fig. 3 Poorly treated coeliac disease. Morphology is grossly abnormal (grade 3) and villi very stunted. RFAL-2 reaction remains strong in brush border of crypt epithelium but is essentially absent from abnormal luminal epithelium.

Fig. 4 Untreated coeliac disease with absence of normal villi (total villous atrophy, grade 4 histology) and pathological damaged luminal epithelium. There is little reaction with RFAL-2; even reaction in crypts is diminished and flattened mucosa is essentially negative.

The immunofluorescence reaction was performed as previously described. ${ }^{22}$ Briefly, sections of tissue were rehydrated in phosphate buffered saline and incubated with $10 \mu \mathrm{l}$ of monoclonal antibody (undiluted culture supernatant, suitably diluted ascites fluid, or purified commercial preparations), washed, and reincubated with fluorescein isothiocyanate conjugated goat antimouse immunoblobulin (Tago,
SeraLab, Crawley Down, Sussex). This conjugate, which cross reacts with rat immunoglobulins, was extensively solid phase absorbed on human immunoglobulins coupled to cellulose carbonate ${ }^{23}$ and glutaraldehyde insolubilised ${ }^{24}$ homogenate of whole human liver to ensure specificity. All incubations lasted 45 minutes at room temperature and were followed by three 5 minute washes in phos- 
phate buffered saline. Controls consisted of omission of primary antibody and substitution with irrelevant antibody. Monoclonal antibodies to $T$ cell subsets and HLA-DR ${ }^{22}$ and fibronectin ${ }^{25}$ were used for this purpose. Preparations were mounted in 20/30 Gelvatol (Monsanto, London) containing diaminobicycloctane and viewed in a Zeiss Standard 18 microscope equipped with epifluorescent illumination and selective filters.

\section{Results}

\section{NORMAL JEJUNUM}

The eight CALLA antibodies gave a characteristic and specific reaction with the brush border of small intestine epithelium of fetal and adult specimens (Fig. 1). Of the antibody panel, only AL1 and BA-2 antibodies to non-CALLA (gp100) antigens with associated leukaemia were negative (Table). The reaction of the anti-CALLA antibodies were unequivocal, ranging in intensity from moderate to strong on fetal and adult jejunum. In adult specimens of normal histology (grade 1) the reaction was equally positive on crypt and villous epithelium. In the fetal small intestine all antibodies except AL1 and BA-2 reacted strongly with enterocytes, although there was a cytoplasmic reaction in some crypt cells, rather than the brush border reaction characteristic of adult jejunal epithelium.

\section{COELIAC DISEASE}

In patients with coeliac disease in whom there was profound histological abnormality (grades 3 and 4) seven anti-CALLA antibodies were still positive with all epithelial cells, although there was a slight tendency for a weaker reaction with the non-crypt luminal surface epithelium with RFAL-3, J5, BA-3, BD-CALLA, and VIL-1A (Table).

Whereas in normal jejunum RFAL-2 reacted strongly with the entire villous and crypt epithelium (Fig. 1), in biopsies of patients with untreated coeliac disease of grade 4 histology RFAL-2 reactivity was diminished in the crypts and either weak or absent from the remaining luminal epithelium (Fig. 4). In the patients with treated coeliac disease, ranging in morphology from grade 1 (normal) to grade 3 (severe villous atrophy), RFAL-2 labelling was closely related to the pathological change and degree of atrophy present, almost certainly as a function of the date a gluten free diet was started and strictness of adherence to the diet: the less severe the pathological villous atrophy the stronger the reaction of RF-CALLA along the villi and the more it resembled the normal jejunal pattern. Thus in well treated patients with grade 1 histology the reactivity pattern was the same as in normal jejunum, whereas in poorly treated patients (grades 2 and 3 ) there was much less reactivity on the stunted villi, with a strong reaction observed only in the crypts (Figs. 2 and 3 ).

\section{STOMACH AND LARGE BOWEL}

All antibodies, including the eight anti-CALLA antibodies, were essentially negative on cryostat sections of normal stomach (antrum and body). There was no reaction of anti-CALLA antibodies with the fetal large bowel epithelium or adult large bowel epithelium from patients with normal histology or patients with inflammatory bowel disease (Crohn's disease and ulcerative colitis).

\section{Discussion}

Our results clearly show the strong expression of a moeity related to CALLA in the brush border of normal jejunal epithelium. The essentially negative reaction of anti CALLA antibodies in stomach epithelium and the totally negative reaction in colonic epithelium imply a functional role for the entity similar to common acute lymphoblastic leukaemia expressed in normal jejunal epithelium, related to the functional capacity of these cells. Notwithstanding the clinical implications for direct immunotherapy with anti-CALLA monoclonal antibodies to remove residual leukaemic cells, ${ }^{26}$ the finding that anti-CALLA antibodies react with normal jejunal epithelium suggests that such antibodies may be useful probes for the study of absorbtive intestinal enterocytes. Especially useful in this context would be the antibody RFAL-2 in view of its apparent ability to discriminate normal from damaged jejunal epithelium.

The functional importance of the 90-100 kilodalton (gp100) CALLA entity, either on common acute lymphoblastic leukaemia cells or on their normal haemopoietic cell progenitors, is not clear. Possibly, CALLA may be involved in absorptive processes, given its strong expression by kidney epithelium. ${ }^{10}$ The CALLA expressed by various non-lymphoid cells tends to differ slightly in molecular weight from CALLA that has been immunoprecipitated from leukaemic cells. ${ }^{910}$ It is therefore likely that "gp100 CALLA" subsumes a group of related cell surface molecules, sharing a degree of immunological similarity (and presumably sequence homology) and expressed by a variety of normal and malignant cells in different variant forms. This view is supported by the different tissue localisation patterns of different anti-CALLA antibodies (unpublished observations) emphasised in this study.

Also of interest is a recent report of a 90 kilodalton protein of rat renal and intestinal brush border 
identified with monoclonal antibody, ${ }^{27}$ although its relation to CALLA was not investigated. The overwhelming probability is that different CALLA antibodies recognise different epitopes of the CALLA expressed by common acute lymphoblastic leukaemia cells (which need not necessarily be shared by CALLA homologues expressed by nonlymphoid cells).

Whether CALLA is, indeed, associated with absorbtive functions and the microvilli of brush border structures remains to be determined. Our data suggest that the particular epitope identified by RFAL-2 may, indeed, be part of a functional molecule, as loss of the RFAL-2 marker correlates with the damage to epithelial cells and the severely reduced absorbtive capacity associated with coeliac disease. We suggest that RFAL-2 may be a particularly valuable reagent in the study of jejunal brush border, both for its practical application as a sensitive marker for pathological change and as a means of elucidating the structure and function of microvillous absorptive epithelia.

This work was supported in part by grants from the Leukaemia Research Fund (London) and from the Yorkshire Regional Health Authority. We thank Drs J Kersey, Anne-Marie LeBacq, and Professor W Knapp for their generous gifts of antibodies; Dr C Milstein for providing the NSO/ 1 myeloma cell line used to generate the RFAL monoclonal antibodies; Dr M Bofill for testing the fetal material; and Drs BJ Rathbone, S Badr El-Din, C Smart, and the surgeons of the hospitals in the Leeds Eastern Health Authority for cooperation and help in providing specimens from patients.

\section{References}

' Greaves MF, Brown G, Rapson NT, Lister TA. Antisera to acute lymphoblastic leukaemia cells. Clin Immunol Immunopathol $1975 ; 4: 67-72$.

${ }^{2}$ Greaves M, Delia D, Janossy G, et al. Acute lymphoblastic leukaemia associated antigen. IV. Expression on nonleukaemia 'lymphoid' cells. Leuk Res 1980;4:15-23.

${ }^{3}$ Jannosy G, Bollum FJ, Bradstock KF, McMichael A, Rapson N, Greaves MF. Terminal transferase positive human bone marrow cells exhibit the antigenic phenotype of common acute lymphoblastic leukaemia. J Immunol 1979; 123:1525-62.

${ }^{4}$ Ritz J, Pesando JM, Notis-McConarty J, Lazarus H, Schlossman SF. A monoclonal antibody to human acute lymphoblastic leukaemia antigen. Nature 1980;283:583-4.

${ }^{5}$ LeBien T, Kersey J, Nakazawa S, Minato K, Minowada J. Analysis of human leukaemia/lymphoma cell lines with monoclonal antibodies BA-1, BA-2 and BA-3. Leuk Res 1982;6:299-305.

- LeBacq-Verhayden AM, Ravoet AM, Bazin H, Sutherland DR, Tidman N, Greaves MF. Rat AL2, AL3, AL4 and AL5 monoclonal antibodies bind to the common acute lymphoblastic leukaemia antigen (CALLA gp100). Int $J$ Cancer 1983; 32: 273-9.

' Knapp W, Majdic O, Bettelheim P, Liszka K. VIL-A1, a monoclonal antibody reactive with common acute lymphatic leukaemia cells. Leuk Res 1982;6:137-47.
${ }^{8}$ Cossman J, Neckers LM, Leonard WJ, Greene WC. Polymorphonuclear neutrophils express the common acute lymphoblastic leukaemia antigen. J Exp Med 1983;157:1064-9.

' Braun MP, Martin PJ, Ledbetter JA, Hansen JA. Granulocytes and cultured human fibroblasts express common acute lymphoblastic leukaemia-associated antigens. Blood 1983; 61:718-25.

${ }^{10}$ Metzgar RS, Borowitz MJ, Jones NH, Dowell BL. Distribution of common acute lymphoblastic leukaemia antigen in nonhematopoietic tissues. J Exp Med 1981;154:1249-54.

" Carrel S, Schmidt-Kessen A, Mach J-P, Heumann D, Girardet C. Expression of common acute lymphoblastic leukaemia antigen (CALLA) on human malignant melanoma cell lines. $J$ Immunol 1983; 130: 2456-60.

12 Carrel S, De Tribolet N, Gross N. Expression of HLA-DR and common acute lymphoblastic leukaemia antigens on glioma cells. Eur J Immunol 1982;12:354-7.

${ }^{13}$ Kenny JA, Booth AG. Microvilli: their ultrastructure, enzymology and molecular organisation. Essays Biochem 1978;14: $1-44$.

14 Wright NA. Cell proliferation in the normal gastrointestinal tract. Implications for proliferative responses. In: Cell proliferation in the gastrointestinal tract. Appleton DR, Sunter JP, Watson AJ, eds. Tunbridge Wells: Pitman Medical 1980:3-21.

is Watson AJ, Wright NA, Appleton DR. Cell proliferation in normal, convoluted and avillous small-intestinal mucosae of man. In: Appleton DR, Sunter JP, Watson AJ, eds. Cell proliferation in the gastrointestinal tract. Tunbridge Wells: Pitman Medical, 1980:351-63.

16 Shiner M. Ultrastructure of the small intestinal mucosa. Normal and disease-related appearances Berlin: Springer-Verlag, 1983.

17 Falchuk ZM. Gluten-sensitive enteropathy. Clin Gastroenterol 1983;12:475-94.

${ }^{18}$ Scott BB, Losowsky MS. Patchiness and duodenal-jejunal variation of the mucosal abnormality in coeliac disease and dermatitis herpetiformis. Gut 1976;17:984-92.

${ }^{19}$ Galfré G, Milstein C. Preparation of monoclonal antibodies: strategies and procedures. Methods Enzymol 1981;73:3-51.

${ }^{20}$ Minowada J, Janossy G, Greaves MF, et al. Expression of an antigen associated with acute lymphoblastic leukaemia in human leukaemia-lymphoma cell lines. Journal of the National Cancer Institute 1978;60:1269-77.

${ }^{21}$ LeBacq AM, Ravoet AM, Bazin H, de Bruyere M, Rodhain J, Sokal G. Complementary anti-CALLA like monoclonal antibodies. In: Bernard A, Boumsell L, eds. First workshop of human leukocyte differentiation antigen. Berlin: SpringerVerlag, 1983.

${ }^{22}$ Malizia G, Trejdosiewicz LK, Wood GM, Howdle PD, Janossy G, Losowsky MS. The microenvironment of coeliac disease: T-cell phenotypes and expression of the $\mathrm{T} 2$ ' $\mathrm{T}$-blast' antigen by small bowel lymphocytes. Clin Exp Immunol 1985;60:437-46.

${ }^{23}$ Catty D, Kennedy JF, Drew RL, Chotum H. The application of cellulose carbonate to the preparation of water-insoluble immunoabsorbents used in the purification of antibodies to immunoglobulins. J Immunol Methods 1973;2:353-67.

${ }^{24}$ Avrameas S, Ternynck T. Biologically active water-insoluble protein polymers. I. Their use in isolation of antigens and antibodies. J Biol Chem 1967;242:1651-7.

${ }^{25}$ Trejdosiewicz LK, Southgate S, Hodges GM, Goodman SL. Micro-heterogenous expression of peanut agglutinin-binding sites in the extracellular matrix of cultured cells. Exp Cell Res 1985; 156: 153-63.

${ }^{26}$ Ritz J, Pesando JM, Sallan SE, et al. Serotherapy of acute lymphoblastic leukaemia with monoclonal antibody. Blood 1981;58:141-52.

${ }^{27}$ Ronco $\mathrm{P}$, Allegri L, Melcion C, et al. A monoclonal antibody to brush-border and passive Heymann nephritis. Clin Exp Immunol 1984;55:319-32.

Requests for reprints to: Dr LK Trejdosiewicz, Department of Medicine, St James's University Hospital, Leeds LS9 7TF, England. 